\title{
Experimental and modeling investigation of sewage solids sedimentation based on particle size distribution and fractal dimension
}

\author{
*J. Wu; C. He \\ School of Environmental Engineering and Science, Yangzhou University, 225000, China
}

Received 25 July 2009; $\quad$ revised 27 September 2009; accepted 2 November 2009; available online 1 December 2009

\begin{abstract}
Sewage solids are usually characterized by non-specific parameters such as suspended solids. The suspended solids has been shown to be an inadequate index for advanced water treatment processes. In this study, the sewages solids particle size distribution was used to provide more detailed information on sewage characteristic. It is hoped that, by introducing particle size distribution, the mechanism of sewage solids sedimentations can be better understood. The particle size distribution of the domestic sewage was measured by the Malvern ${ }^{\circledR}$ laser scattering technique to link to its settlement efficiency. Experimental results show that $77 \%$ of particle volume was removed during the 90 min settling, of which $71.2 \%$ of particle volume was removed in the initial $30 \mathrm{~min}$. The submicron particles were found to be removed by co-settling with large particles. The fractal dimensions of sewage solids could also be derived from the laser scattering measurement. The fractal dimension could also provide useful information on the shape and density of sewage solids. A mathematical model considering the particle sizes, shapes and density changes was then constructed to simulate the settlement of raw sewage particles. Comparison of the modeling results based on discrete and flocculant settling theory shows that settlement can be better predicted by considering the fractal nature of particles. The particle size distribution and fractal dimension data measured by Malvern ${ }^{\circledR}$ laser scattering technique have been shown to be valuable data for in-depth understanding of the mechanisms of sewage solids sedimentation.
\end{abstract}

Keywords: Discrete settling; Flocculant settling; Laser scattering; Solids sedimentation mechanism; Suspended solids

\section{INTRODUCTION}

During sewage treatment process, primary settling tank (PST) is used as a preliminary step to remove settleable solids. Due to the complex nature of sewage, the current practice is to quantify sewage as nonspecific parameters such as chemical oxygen demand (COD) and suspended solids (SS) (Pasztor et al., 2009). The designing of PST is usually based on the SS concentration (Metcalf and Eddy 2002). However, the SS might not be the adequate measurement. For example, some contaminants are better to be characterized by number or surface area (Lawler, 1978; Chavez, 2004) and a modeling study by Lawler (1978) has shown that the effectiveness of the solid-liquid separation processes is different when the sewage with same SS, but in different The particle size distribution (PSD) was treated.

During the settling process, large particles with high

*Corresponding Author Email: jun.wu08@gmail.com Tel.: +8615205 278 805, Fax: +86 51487978626 settling velocity usually can settle. Small particles with low settling velocity will be flushed out of the primary settling tank before they can settle to the bottom of the tanks. As the PSD in sewage will affect their velocity of settling, the PSD of the sewage play important roles in the settling behavior of the material in sewage (Sui et al., 2008). However, determination of the entire PSD of sewage solids is likely to be prohibitively expensive and time consuming, until recently PST design has been based on more easily measured characteristics of particles such as SS. Recent developments in the technology of PSD measurement. However, provide methods for determining the number densities and size distribution of particles. The PSD in the sewage has been examined by many previous researchers (Lawler, 1978; Li, 1993). The effect of PSD on the settleability of particles from combined sewer overflows (CSOs) has been studied by Shin et al. (2001) and Cho and Michelengel (2008). However, most of the PSD in these 
literatures was analyzed by serial filtration which is time consuming and cannot be carried out routinely. The PSD measured by laser scattering will be used to study their effect on the settleability of solids in sewage in the research.

PSD has been increasingly gaining acceptance in the design and assessment of water treatment process. Levine et al. (1991) studied the impact of PSD of particulate contaminants on their treatability. Various authors have used PSD to evaluate the performances of trickling filters (Zahid and Ganczarczyk, 1990; Marquet et al., 1999, 2007; Schubert and Günthert, 2001). Dulekgurgen et al. (2006) tried to relate the different fractions of COD in wastewater to its PSD and used PSD as an index for wastewater biodegradability. PSD has also been used as a tool to evaluate the effect of ultrasound on the suspended particles in wastewater (Gibson et al., 2009). Ofir et al. (2007) studied the effect of zeta-potential on particle size during electroflocculation. Particle number density is also an area of interests during wastewater treatment process. Karapinar and Kargi (1996) studied the effect of particle number density on wastewater treatment performance of a fluidized-bed bioreactor. PSD analysis has also been applied into the activated sludge process to investigate the sludge floc properties (Andreadakis 1993; Barbusinski and Koscielniak 1995; Wilen and Balmer, 1999; Biggs and Lant, 2000; Chaignon et al., 2002; Harikumar et al., 2009). PSD could also be used in the membrane bio-reactor (MBR) studies due to its direct impact on membrane fouling (Shimizu et al., 1997; Wisniewski et al., 2000; Lim and Bai 2003; Stoller 2009).

In most of cases concerning unit operations for particle removal, the particles are assumed to be spherical, which is not correct in sewage suspension. By adopting the equivalent sphere assumption, some vital information has been loosed regarding the shape of particles. The fractal dimension $D_{f}$, is a statistical quantity that gives an indication of how completely a fractal appears to fill space (Mandelbrot 1982). For linear, planar and three dimensionally compact objects, the exponent $D_{f}$ will take the values of $1,2,3$, respectively while porous aggregates such as activated sludge flocs, have fractal values typically in the range 1.7-2.5 (Guan et al., 1998). A high fractal value indicates compact particles whereas low values correspond to loose aggregation of particles. The fractal dimension has been used to measure the compactness of particles (Guan, et al., 1998; Spicer et al., 1998; Wilen et al., 2003).
It is hoped that, by introducing the PSD and particle fractal dimension, the mechanism of sewage solids settling in primary settling tank can be better understood and then, the design of the primary settling tank can be enhanced. The experiment was carried out in Loughborough, United Kingdom during July 2006 to April 2007.

\section{MATERIALS AND METHODS}

The sewage sample was collected from the Loughborough (UK) sewage treatment works after screening treatment (2007). The works serves a population equivalent of 70,000. Dry weather Flows 57 (DWF) average $21 \mathrm{ML}$ /day with a Full Flow (FF) at three times the DWF 58 at $699 \mathrm{~L} / \mathrm{sec}$. The collected samples were stored in refrigerator and analyzed within $24 \mathrm{~h}$.

\section{Particle sizing by Malvern}

PSD of the effluent was measured by the Malvern ${ }^{\circledR}$ Mastersizer 2000, which works on the principle of laser detraction. The Malvern ${ }^{\circledR}$ Mastersizer can measure the particles in size range of $0.02 \mu \mathrm{m}$ to $2000 \mu \mathrm{m}$. The PSD by the Malvern ${ }^{\circledR}$ Mastersizer were based on 7 measurements average.

Fractal dimension calculated by laser scatting method

The fractal value can be calculated from the light scattering data from the Malven Mastersizer according to a method used by a number of researchers (Guan, et al., 1998; Spicer, et al., 1998; Wilen, et al., 2003). This technique is based on a power law relationship between the total scattering intensity (I) of light by the particle and the magnitude of the scattering vector $(q)$ as shown in Eq. 1:

$I(q) \infty q^{-D_{f}}$

If a beam of light is directed on the sample, the intensity of the scattered light can be measured as a function of wave vector $q(q=4 \pi n / \lambda \sin (\theta / 2)$, where $n$ is the refractive index, $\lambda$ is the wavelength of the light and $\theta$ is the scattering angle) which can be calculated from the raw data (the scattering angles from the detectors are supplied by Malvern Instruments). The scattering intensity $(I)$ at each detector was derived from the Malvern measurement results. By plotting the log of the light intensity $(I)$ as a function of the log of the light scattering vector $(q)$. The fractal dimension $\left(D_{f}\right)$ was calculated as the negative linear slope (Guan, 1998). The calculation of fractal dimension of particles in raw sewage in this research is illustrated in Fig. 1. 
Log intens ity vers us Log Angle

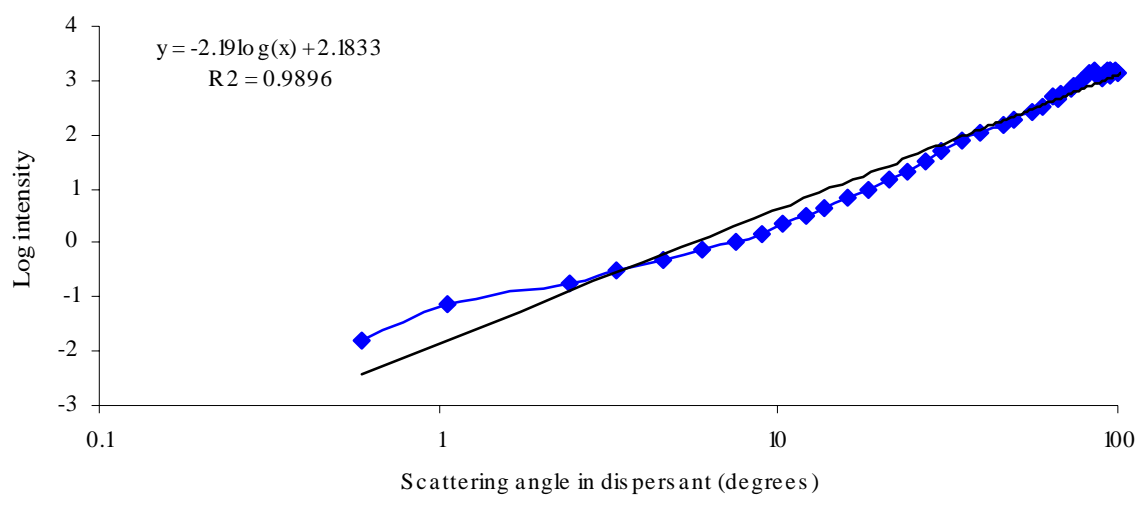

Fig. 1: Calculation of fractal dimension of particles in raw sewage

Light intensity ( $I$ ) data measured by Malvern Mastersizer 2000 is exported to plot the $\log (I)$ vs $\log$ (q) graph. The negative linear slope 2.19 is the fractal dimension of the particles in raw sewage.

\section{Lab settling experiment}

The batch settling experiment was carried out in a 2 $\mathrm{L}$ cylinder. The samples were collected from a depth of $30 \mathrm{~cm}$ below the water surface. The PSD of the sewage after $30 \mathrm{~min}$ and $90 \mathrm{~min}$ settlement were measured by Malvern ${ }^{\circledR}$ Mastersizer 2000.

\section{Model development}

Particle settling can be classified into four categories: (i) Type I: Discrete particle settling refers to the sedimentation of particles in a suspension where solid concentration is low. Particles settle as individuals. There is no significant interaction between neighbouring particles; (ii) Type II: Flocculant settling refers to the sedimentation of particles in a rather dilute suspension. During the settlement, the particles coagulate together, result in the increasing of particle volume and settling velocity; (iii) Type III: Hindered settling, refers to suspension of intermediate concentration, in which inter-particle forces are sufficient to hinder the settling of neighbouring particles. (iv)Type IV: compression settling refers to settling in which the particles are concentrated such that a structure is formed, and further settling can occur only by compression of the structure (Metcalf, 2002).

The Type I settlement usually applies to the removal of grit and sand particles from sewage. The Type II settlement happens in the removal of a portion of suspended solids in primary settling tank.

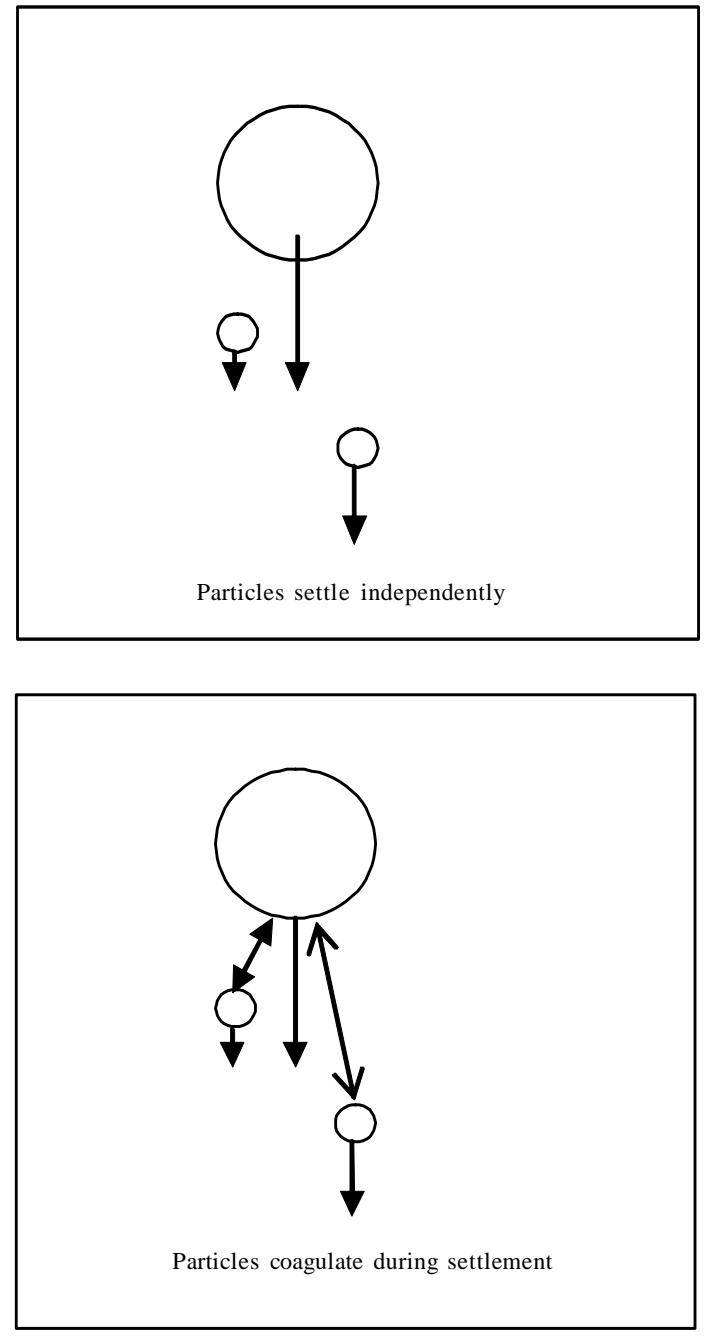

Fig. 2: Discrete settling and coagulation during settlement 
However, raw sewage entering into the primary settling tank is traditionally considered as discrete particle settling for simplification of the calculations. The graphic presentation of Type I and Type II settlement are shown in Fig. 2.

An unequal vertical distribution of particle size occurs due to the settlement. The effective settling volume is divided into 5 layers. The particle size range from $0.02 \mu \mathrm{m}$ to $2000 \mu \mathrm{m}$ is divided into 100 equal logarithmic classes to suit the Malvern scale. Fig. 3 shows how the settlement in the measuring cylinder is simplified in mathematic terms.

$\frac{d n_{k, m}}{d t}$ is the particle number change rate of particles in $m$ layer and with size $k$. With 5 vertical layers and 100 size classes, a total of 500 particle number changes were considered in the model to cover all the particles in the different layers and the different size classes Eq. 2.

$\frac{d n}{d t}=\frac{\left\{\begin{array}{lllll}\frac{d n_{1,1}}{d t} & \frac{d n_{2,1}}{d t} & \frac{d n_{3,1}}{d t} & \cdots & \frac{d n_{100,1}}{d t} \\ \frac{d n_{1,2}}{d t} & \frac{d n_{2,2}}{d t} & \frac{d n_{3,2}}{d t} & \cdots & \frac{d n_{100,2}}{d t} \\ \frac{d n_{1,3}}{d t} & \frac{d n_{2,3}}{d t} & \frac{d n_{3,3}}{d t} & \cdots & \frac{d n_{100,3}}{d t} \\ \frac{d n_{1,4}}{d t} & \frac{d n_{2,4}}{d t} & \frac{d n_{3,4}}{d t} & \cdots & \frac{d n_{100,4}}{d t} \\ \frac{d n_{1,5}}{d t} & \frac{d n_{2,5}}{d t} & \frac{d n_{3,5}}{d t} & \cdots & \frac{d n_{100,5}}{d t}\end{array}\right\}}{\mathrm{k}=1: 100}$ $\frac{d n_{k, m}}{d t}$ can be expressed from the following equation:

For type 1 settling model

$\frac{d n_{k, m}}{d t}=\frac{v_{k}}{z} n_{k, m-1}-\frac{v_{k}}{z} n_{k, m}$

The first item in the right hand side of Eq. (3) describes the addition of particles with size $k$ from the above $(m-1)^{t h}$ layer. The second item represents the loss the particles with size $k$ in $m$ layer by settling down to $(m+1)^{t h}$ layer. $v_{k}$ is the settling velocity of particle of size $k$ calculated from the Stokes Law.

For a type 2 settling model

$$
\begin{aligned}
& \frac{d n_{k, m}}{d t}=\frac{1}{2} \sum \beta(i, j) \cdot n_{i, m} \cdot n_{j, m}-n_{k, m} \sum_{i=1}^{75} \beta(i, k) \\
& \cdot n_{i, m}+\frac{v_{k}}{z} n_{k, m-1}-\frac{v_{k}}{z} n_{k, m}
\end{aligned}
$$

In the type 2 settling model, the particle number changes in each layer due to flocculation as noted in addition to the sedimentation of particles. The first two items in Eq. 4 describes the rate of changes in the number of particle of size $k$ in $m^{\text {th }}$ layer due to flocculation.

By integrating the 500 equations over a 30 and 90 min settlement period, the PSD profiles after 30 or 90 min settling can be predicted.

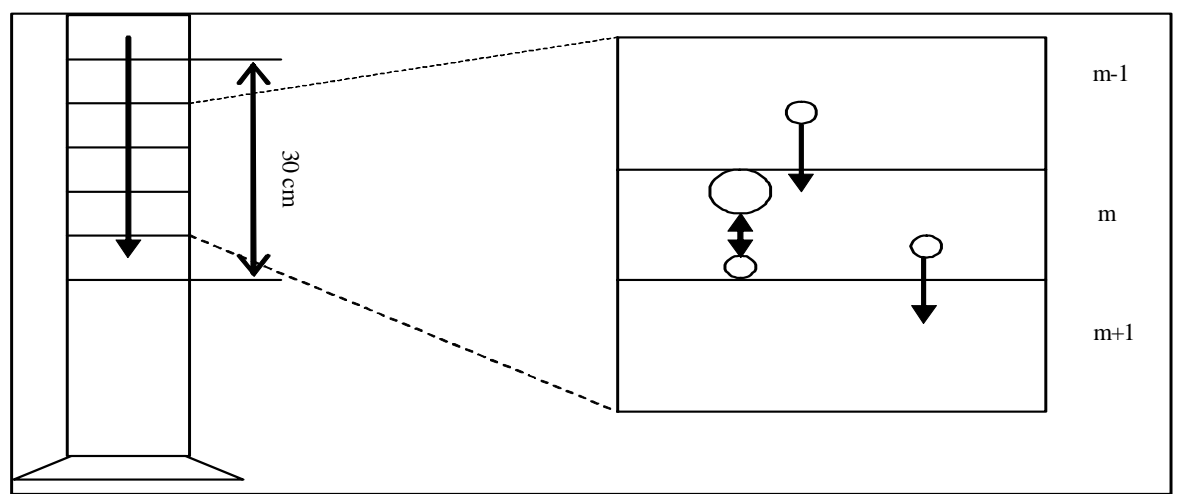

Fig. 3: Partition of sedimentation cylinder for model calculation 


\section{RESULTS AND DISCUSSION}

PSD of raw and settled sewage

PSD whether expressed as number or volume means differently. The number based PSD is dominated by smaller particles and the volume based PSD is dominated by large particles. Both Volume and number based results are presented here.

\section{Volume based PSD results}

The particles measured range from $0.02 \mu \mathrm{m}$ to 2000 $\mu \mathrm{m}$ and are divided into 100 size intervals equally distributed in a logarithmic scale. The results shown in Fig. 4 are averaged from six duplicate measurements. It can be seen that the sewage particles range from 0.4$900 \mu \mathrm{m}$. Similar results has been derived by Azema et al. (2002). Laser diffraction is a straightforward method for particle size measurement. However, a physical limit of the laser diffraction method exists when the particle size is in the size range of the wavelength $(0.43 \mu \mathrm{m}$ for the Malvern 2000) of the laser light. The measurement results for these particles can be of great uncertainty.

There is a major particle volume reduction at the initial 30 min settling. The area between two distribution

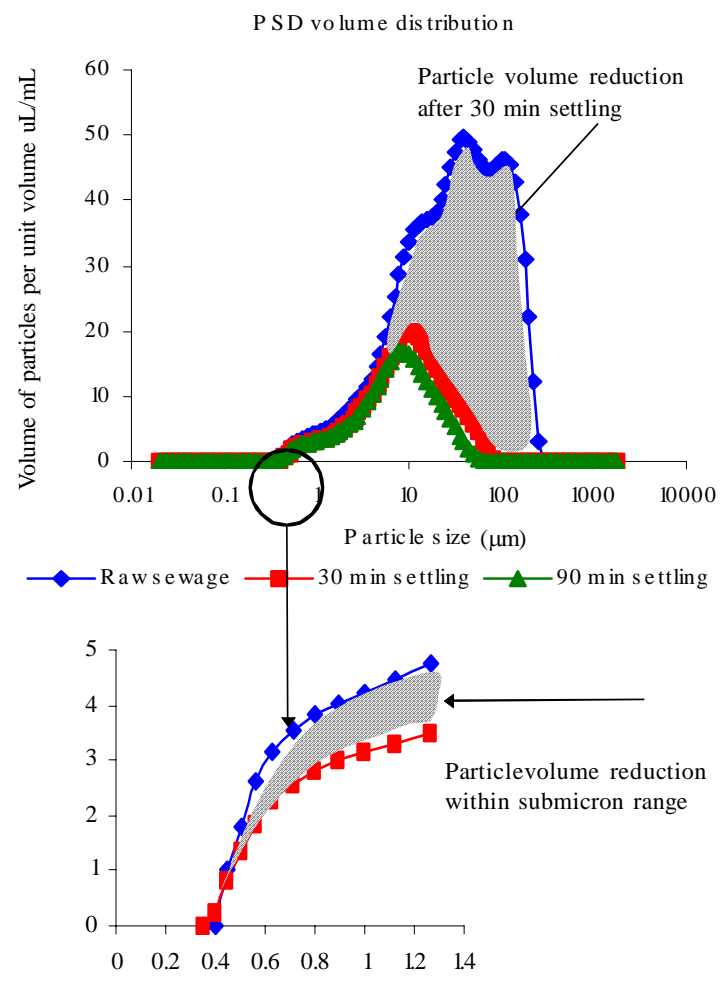

Fig. 4: Particle volume concentration of raw and settled sewage graphs after different settling periods is the particle volume reduction during that settling period. For example, the total volume of particles was reduced from $1414 \mu \mathrm{L} / \mathrm{mL}$ to $407 \mu \mathrm{L} / \mathrm{mL}$ after the $30 \mathrm{~min}$ settling with a total particle volume reduction of $1007 \mu \mathrm{L} / \mathrm{mL}$. After 90 min settling, the volume was reduced to $324 \mu \mathrm{L} / \mathrm{mL}$, a total volume reduction of $1090 \mu \mathrm{L} / \mathrm{mL}$ or $77 \%$ of the particle volume was removed during the 90 mins settling of which $71.2 \%$ of the volume of particles were removed in the initial 30 first settling. These are the large particles, which occupy the major percentage of particle volume. This indicates that over-design settlement tanks could have adverse effects and that design improvement should focus on the hydraulics features to improve coagulations.

Compared to the particle volume reduction for large particles, the particle volume reduction for submicron particles was not significant. The total volume of submicron particles was reduced from $24 \mu \mathrm{L} / \mathrm{mL}$ to 18 $\mu \mathrm{L} / \mathrm{mL}$ after 30 min settling and there was no submicron particle volume reduction from 30 min settling to 90 min settling. In the 90 min settling, only $0.5 \%$ of volume reduction is contributed by submicron particles. Further interpretation of this data would indicate that increases in HRT time without flocculation and particle enlargement would not improve performance. According to the Stokes law, the settling velocity of submicron particles is not big enough to settle these particles in the time available (i.e. 90 mins calculation not shown). This suggests that the submicron particles will not settle themselves

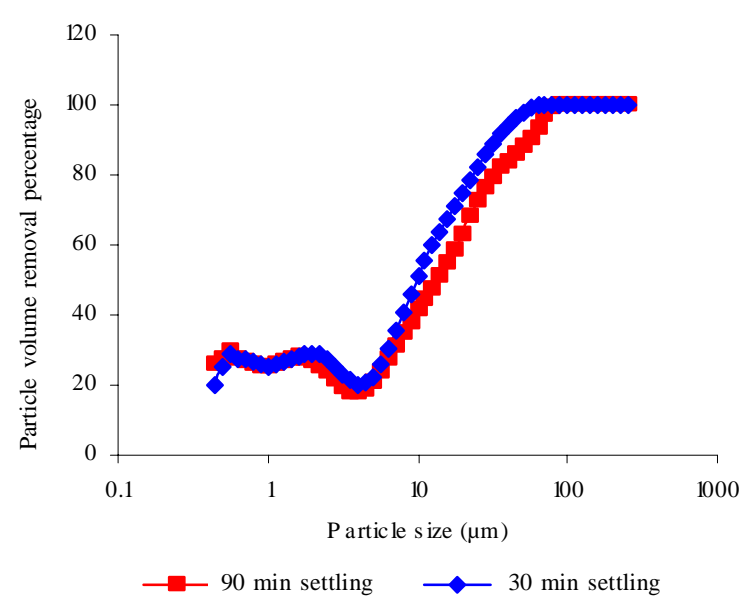

Fig. 5: Particle volume removal rates of different sizes 
unless attach to the larger particles.

Fig. 5 shows the volume removal rate of particles with different particles sizes. It can be seen that for particles between 0.4-5 $\mu \mathrm{m}$, the removal rate was between $20-30 \%$. For particles between 5-100 $\mu \mathrm{m}$, the removal rates increased in proportion to the corresponding particle size. Particles larger than 100 $\mu \mathrm{m}$ are completely removed as predicted by Stokes law assuming a particle density of $1.3 \mathrm{~kg} / \mathrm{L}$. The likely explanation is that for the particles between 0.4-5 $\mu \mathrm{m}$ has too low a settling rate by gravity. If it is the case, then Stokes law is inappropriate to simulate the settling of these small particles. For particles larger than $5 \mu \mathrm{m}$, gravity is the dominant factor affecting their settling velocity, which increases with particle size

\section{Number based PSD results}

Fig. 6 shows particle number changes during the settlement process. The removal of submicron particles mainly happens in the first 30 min settling, during which the majority of large particles settle down. No significant submicron particles settlement was observed after 30 min settling. This suggests that the small particles are co-settled with large particles by sweeping, adsorption or flocculation, which indicates some improvements in mixing in the inlet rather than increasing the retention time to improve performance. The modeling study of the fluctuation of raw water particles by Lawler (1978)

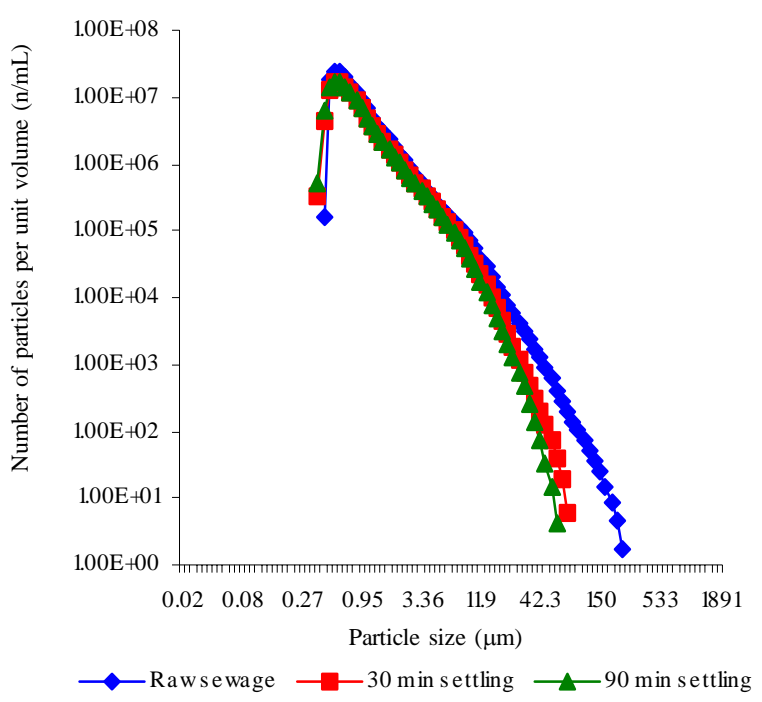

Fig. 6: Number based PSD presented in Log scale also indicated that the reduction of submicron particle concentration was more effective if large particles were present. The Lawler modeling study compared the treatment performance from raw water with power law PSD (equation 3-8) having $\beta=3$ and $\beta=4$. The raw water with $\beta=3$ have substantially more particles in the larger sizes than water with the same solid concentration and size range but with $\beta=4$. The particle removal efficiency particular for submicron particles were higher for the $\beta=3$ PSD than $\beta=4$. The results in this study and the modeling study by Lawler have both shown that the solids removal efficiency

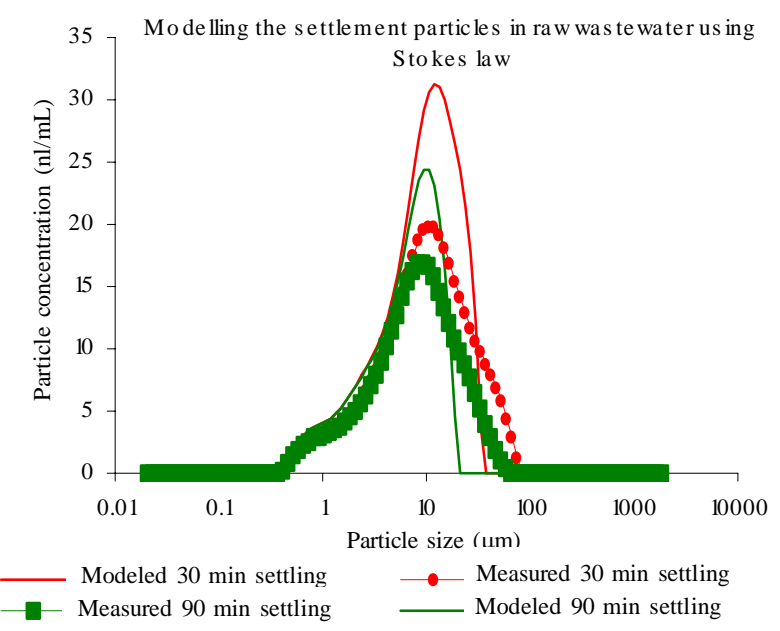

Fig. 7: PSD Modelled results according type I settling

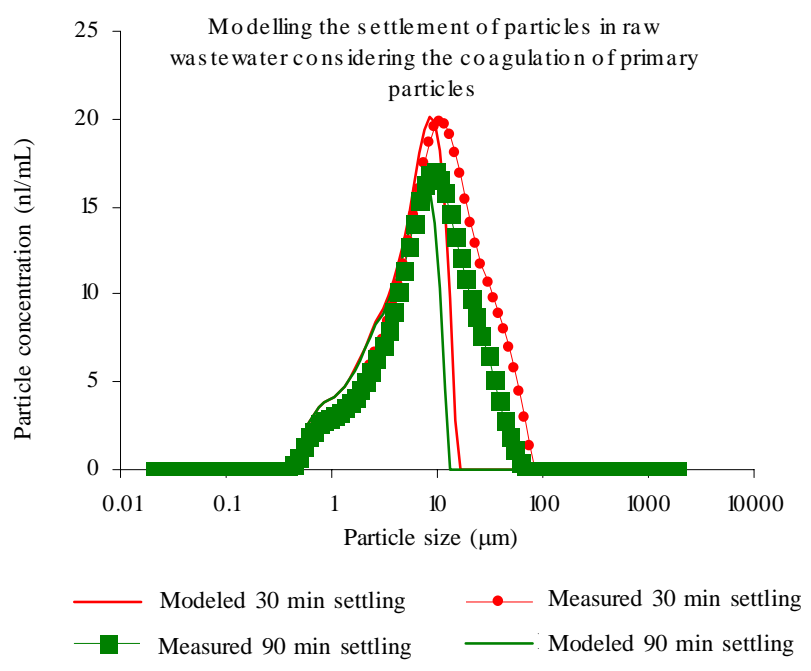

Fig. 8: PSD Modelled results according type II settling 
can be improved by altering the PSD and knowledge of the PSD.

\section{Modeling results}

The modeled results according to type I and type II settling are shown in Figs. 7 and 8 and compared with the measured results. It can be seen that without considering the flocculation effect in the type I modeling, the settling efficiency for smaller particles are underestimated by $30 \%$. The type II modeling on the other hand has satisfactory modeling results for smaller particles. The model also overestimates the efficiency of the removal of the larger particles. The actual behavior of the submicron particles on the other hand fits the model rather well.

The actual settling speed of larger particles is not as fast as was predicted. A possible explanation for this is that in the above model the density of particles is considered to constant, but a number of studies have suggested that density is not uniform. In a particular study by Lagvankar et al. (1968) it was found that flocs generated during drinking water treatment reduced in densities with increasing size. Similar observations were reported by Tambo et al. (1979).

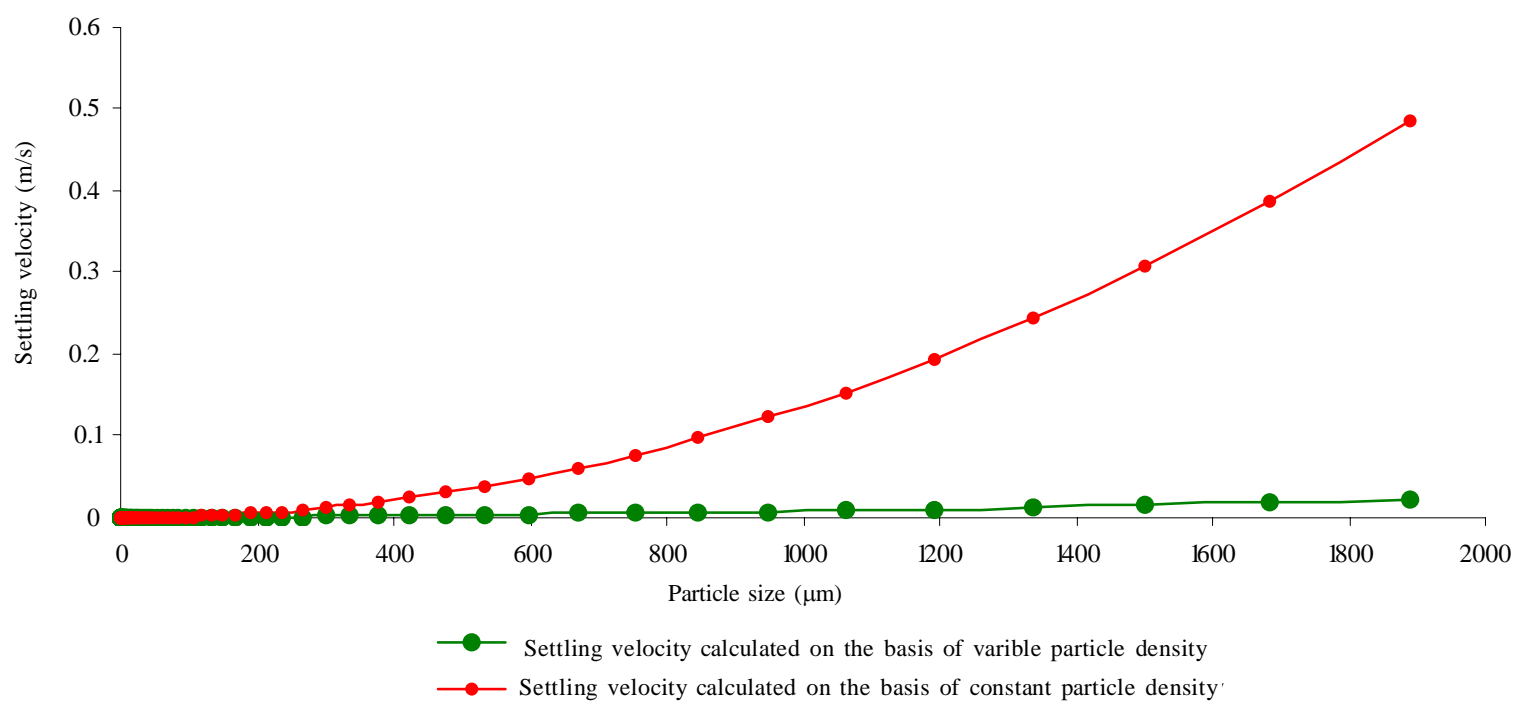

Fig. 9: Particle settling velocity calculated on constant and variable particle density

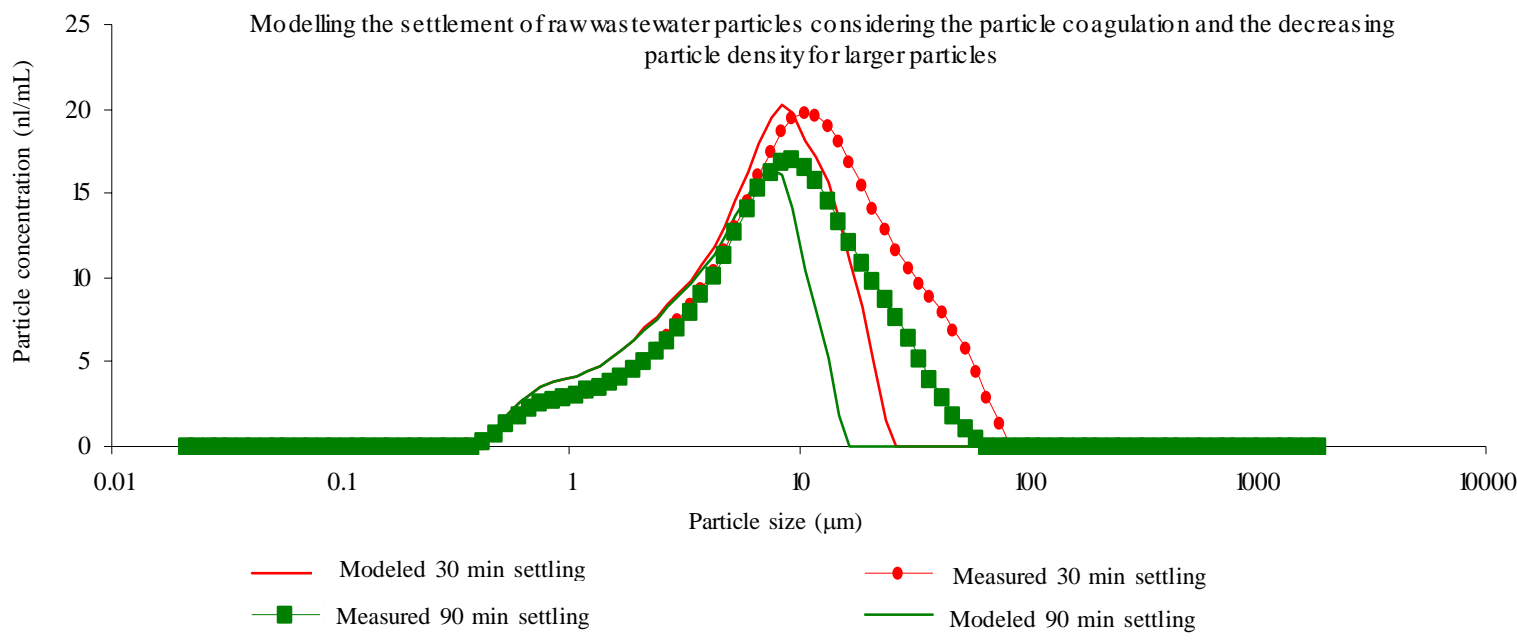

Fig. 10: PSD modeling results considering decreasing density for larger particles 
The density difference between the settling particles and the liquid medium $\Delta \rho$ used in calculation of settling velocity is simply expressed as:

$\Delta \rho=\rho_{S}-\rho_{L}$

Where the $\rho_{s}$ and $\rho_{L}$ are the solids density and liquid medium density respectively.

When the $\Delta \rho$ is plotted against the particle diameter in log-log form, a linear relation ship is often found, suggesting a relationship in the following form:

$\Delta \rho=B a^{-y}$

$B$ and $y$ are constants, $a$ is particle diameter. $y$ is a constant that related to the fractal dimension $D_{f}$

$D_{f}=3-y$

Thus, the introduction of the fractal dimension $D_{f}$ as a parameter can be used to better represent the compactness of particles. The completely solid particles would then have a fractal dimension $D_{f}$ value of 3 as noted above. The density difference $\Delta \rho$ will be independent of particle diameter since the constant $y$ would have a value of 0 . The fractal dimension values of many suspensions including mineral particles, activated sludge are usually in the range of 1.5-2, corresponding to the $y$ constants of $1-1.5$. Thus, if increasing the particle size results in a reduction of particle density then adjustment to the basic equation is needed. The actual increase in the settlement velocity due to particle size increases is less than the velocity improvement calculated on the basis of constant particle density.

Fig. 9 is a comparison of settling velocity calculated based on (i) constant particle and (ii) decreasing particle density. A 10 fold increasing in sizes from $200 \mu \mathrm{m}$ to $2000 \mu \mathrm{m}$ gives a 3 fold increasing in settling velocity rather than a 25 fold increase that would be expected on the basis of constant floc density.

Fig. 10 is the PSD modeling results including a fractal factor for the decreasing in particle settling velocity due to its variable density. The modeled PSD for the larger particles are closer to the measurement results, especially for the $30 \mathrm{~min}$ settling data.The actual particle settling characteristics can usually be obtained by a settling column with sampling ports inserted at approximately $0.5 \mathrm{~m}$ intervals. The samples can be taken at various times for solids concentration and PSD analysis. A settling curve can then be derived by plotting the removal percentage against time and heights. With the help of the PSD based settlement model using adjustment from particle fractals, the PSD and particle concentration of the supernatant can be predicted. All parameters except measured are assumed to be typical values. A critical evaluation of these assumed parameters will have a more accurate model of the primary settling process. It is suggested that this could be used to promote better inlet designs for settlement tasks and so reduce the energy demands. The modeling study shows that the flocculation of primary particles played an important role in improving the solids removal efficiency.

The inlet design should be arranged to promote the flocculation. The solids removal will reduce the burden for the following treatment therefore saving energy.

The traditional Stokes law describes the sedimentation of raw sewage particles as if they have no interaction with each other. The data presented shows this underestimates the sedimentation efficiency by up to $30-40 \%$. Contacts can occur between particles by mechanisms such as Brownian motion, differential settling and sweeping. This results in the flocculation of primary particles and enhanced gravity sedimentation. These particle coagulation mechanisms described are still poorly understood but can be improved using modern analytical techniques to characterize the particle settling properties.

The experiment was carried out in a batch settling environment. It could be useful to test the method to be at a larger full scale primary tank where the hydraulic conditions should be considered. A combination of CFD modeling and improved particle flocculation and settling modeling could produce more sensible results.

\section{CONCLUSION}

Based on the experimental and modeling study, a few conclusions can be drawn:

The laser scattering method was a useful and rapid method of measuring the PSD in sewage.

There was greater particle removal in the initial settlement than the later stages. $77 \%$ of particle volume was removed during the 90 min settling, of which $71.2 \%$ of particle volume was removed in the initial $30 \mathrm{~min}$. The submicron particles were removed by co-settling with large particles. $25 \%$ of the 
submicron particles were removed during the first 30 min settling. No additional submicron particles were removed over the next 60 min settling.

The PSD measurement was shown to provide more information on particle settling, removal mechanisms than the traditional non-specific parameters. The fractal dimension of particles in the sewage was calculated to be 1.91 from the laser scattering data. The fractal nature of the particles in the sewage suggests the existence of porous non-compact particles. The density of these non compact particles decreases with increasing particle size. Improved density and drag terms should be considered in the modeling of primary settlement.

The modeling of the settlement of sewage particles considering the interaction between particles and decreasing density of larger particles was shown to provide a better fit between the modeling data and experimental data than simple stokes rule alone. A better understand of the settling mechanism in PST was achieved using the modeling method.

\section{ACKNOWLEDGMENTS}

The research has been supported by national water pollution control and treatment key scientific project of China, Grant number: 2008ZX07317-007-1. The author also would like to thank Professor Andrew Wheatley from Loughborough University, UK for his constructive advice.

\section{REFERENCES}

Andreadakis, A. D., (1993). Physical and chemical properties of activated sludge floc. Water Res., 27 (12), 1707-1714 (8 pages).

Azema, N.; Pouet, M. F.; Berho, C.; Thomas, O., (2002). Wastewater suspended solids study by optical methods. Colloid Surface A., 204 (1), 131-140 (10 pages).

Barbusinski, K.; Koscielniak, H., (1995). Influence of substrate loading intensity on floc size in activated sludge process. Water Res., 29 (7), 1703-1710 (8 pages).

Biggs, C. A.; Lant, P. A., (2000). Activated sludge flocculation: on-line determination of floc size and the effect of shear. Water Res., 34 (9), 2542-2550 (9 pages).

Chaignon, V. ; Lartiges, B. S.; El Samrani, A.; Mustin, C., (2002). Evolution of size distribution and transfer of mineral particles between flocs in activated sludges: an insight into floc exchange dynamics. Water Res., 36 (3), 676-684 (9 pages).

Chavez, A.; Jimenez, B.; Maya, C., (2004). Particle size distribution as a useful tool for microbial detection. Water Sci. Tech., 50 (2), 179-186 (8 pages).

Cho, S.; Michelangeli, D. V., (2008). Modeling study of the effects of the coagulation kernel with van der Waals forces and turbulence on the particle size distribution. Int. J. Environ. Sci. Tech., 5 (1), 1-10 (10 pages).

Dulekgurgen, E.; Dogruel, S.; Karahan, O.; Orhon, D., (2006). Size distribution of wastewater COD fractions as an index for biodegradability. Water Res., 40 (2), 273282 (10 pages).

Gibson, J. H.; Hon, H.; Farnood, R.; Droppo, I. G.; Peter Seto, P., (2009). Effects of ultrasound on suspended particles in municipal wastewater. Water Res., 43 (8), 2251-2259 (9 pages).

Guan, J.; Waite, T. D.; Amal, R.; Bustamante, H.; Ukasch, R., (1998). Rapid determination of fractal structure of bacteria assemblages in sewage treatment: Implications to process optimisation. Water Sci. Tech., 38 (2), 9-15 (10 pages).

Harikumar, P. S.; Nasir, U. P.; Mujeebu Rahman, M. P., (2009). Distribution of heavy metals in the core sediments of a tropical wetland system. Int. J. Environ. Sci. Tech., 6 (2), 225-232 (8 pages).

Karapinar, I.; Kargi, F., (1996). Effect of particle number density on wastewater treatment performance of a fluidized-bed bioreactor. Enzyme Microb. Tech., 19 (2), 140-144 (5 pages).

Lagvankar, A. L.; Gemmel, R. S., (1968). A size-density relationship for flocs. J. Am. Water, Wks Assoc., 60, 1040-1046 (7 pages).

Lawler, D. F.; O’Melia, C. R.; Tobiason, J. E., (1978). Integral water treatment plant design: particle size and plant performance. Particulates in water. American Chemical Society. Chapter 16, 353-388.

Levine, A. D.; Tchobanoglous, G.; Asano T., (1991). Size distributions of particulate contaminants in wastewater and their impact on treatability. Water Res., 25 (8), 911922 (12 pages).

Li, D.; Ganczarczyk, J. J., (1993). Factors affecting dispersion of activated sludge flocs. Water Environ. Res., 65 (3), 258-263 (6 pages).

Lim, A. L.; Bai, R., (2003). Membrane fouling and cleaning in microfiltration of activated sludge wastewater. J. Membr. Sci., 216 (1-2), 279-290 (12 pages).

Mandelbrot, B. B., (1982) The fractal geometry of nature. W. H. Freeman and Co Ltd.

Marquet, R.; Mietton-Peuchot, M.; Wheatley, A. D., (1999) Characterization of trickling filter effluent by particle size distribution and high performance size exclusion chromatography. Water Res., 33 (6), 1415-1424 (10 pages).

Marquet, R.; Muhammad, N.; Vairavamoorthy, K.; Wheatley, A., (2007). Particle size distribution to assess the performance of trickling filters. Proc. Safe. Environ. Protec., 85 (1), 99-103 (5 pages).

Metcalf and Eddy, (2002). Sewage engineering: Treatment and reuse. $4^{\text {th. }}$ Ed. McGraw Hill Inc, 405-407.

Ofir, E.; Oren, Y.; Adin, A., (2007). Electroflocculation: The effect of zeta-potential on particle size. Desalination, 204 (1-3), 33-38 (6 pages).

Pasztor, I.; Thury, P.; Pulai, J., (2009). Chemical oxygen demand fractions of municipal wastewater for modeling of wastewater treatment. Int. J. Environ. Sci. Tech., 6 (1), 5156 (6 pages). 
Schubert, W.; Günthert, F. W., (2001). Particle size distribution in effluent of trickling filters and in humus tanks. Water Res., 35 (16), 3993-3997 (5 pages).

Shimizu, Y.; Uryu, K.; Okuno, Y.; Sadami Ohtubo, S.; Atsuo Watanabe, A., (1997). Effect of particle size distributions of activated sludges on cross-flow microfiltration flux for submerged membranes. J. Ferment. Bioengin., 83 (6), 583-589 (7 pages).

Shin, E. B.; Yoon, H. S.; Lee, Y. D.; Pae, Y. S.; Hong, S. W.; Joo, B. H., (2001). The effects of particle size distribution on the settleability of CSOs pollutants. Water Sci. Tech., 43 (5), 103-110 (8 pages)..

Spicer, P. T.; Pratsinis, S. E.; Raper, J.; Amal, R.; Bushell, G.; Meesters, G., (1998). Effect of shear schedule on particle size, density and structure during flocculation in stirred tanks. Powder Tech., 97 (1), 26-34 (9 pages).

Stoller, M., (2009), On the effect of flocculation as pretreatment process and particle size distribution for membrane fouling reduction. Desalination, 240 (1-3), 209-217 (9 pages).

Sui, J.; He, Y.; Karney, B. W., (2008). Flow and high sediment yield from the Huangfuchuan watershed. Int. J. Environ. Sci. Tech., 5 (2), 149-160 (12 pages).

Tambo, N.; Watanabe, Y., (1979). Physical aspects of flocculation. I. The floc density function and aluminim floc. Water Res., 13 (5), 409-419 (11 pages).

Wilen, B.; Balmer, P., (1999). The effect of dissolved oxygen concentration on the structure, size and size distribution of activated sludge flocs. Water Res., 33 (2), 391-400 (10 pages).

Wilen, B.; Jin, B.; Lant, P., (2003). Impacts of structural characteristics on activated sludge floc stability. Water Res., 37 (15), 3632-3645 (14 pages).

Wisniewski, C.; Grasmick, A.; Leon Cruz, A., (2000). Critical particle size in membrane bioreactors: Case of a denitrifying bacterial suspension. J. Membr. Sci., 178 (12), 141-150 (10 pages).

Zahid, W. M.; Ganczarczyk, J. J., (1990). Suspended solids in biological filter effluents. Water Res., 24 (2), 215-220 (6 pages).

\section{AUTHOR (S) BIOSKETCHES}

Wu, J., Ph.D., Lecturer, School of Environmental Engineering and Science, Yangzhou University, 225000, China.

Email:jun.wu08@gmail.com

He, C., Ph.D., School of Environmental Engineering and Science, Yangzhou University, 225000, China. Email: hcd@yzu.edu.cn

How to cite this article: (Harvard style)

$W u, J . ; H e, C .,(2010)$. Experimental and modeling investigation of sewage solids sedimentation based on particle size distribution and fractal dimension. Int. J. Environ. Sci. Tech., 7 (1), 37-46. 